doi https://doi.org/10.31977/grirfi.v21i3.2436

Recebido: 19/06/2021 | Aprovado: 30/09/2021

Received: 06/19/2021 | Approved: 09/30/2021

\title{
SOBRE A ATUALIDADE E PERTINÊNCIA DAS CRÍTICAS DE NIETZSCHE À EDUCAÇÃO DE SEU TEMPO
}

José Elielton de Sousa ${ }^{1}$

Universidade Federal do Piauí (UFPI)

(iD) https://orcid.org/0000-0002-5288-0703

E-mail: jose_elielton@yahoo.com.br

RESUMO:

O presente texto visa demonstrar a atualidade e a pertinência da crítica de Nietzsche à educação do seu tempo, especialmente aquelas feitas no texto Sobre o futuro dos nossos estabelecimentos de ensino, perante as finalidades e objetivos da educação brasileira, especialmente da educação básica em nível médio, descritos na Lei de Diretrizes e Bases da Educação Nacional (LDB) e na Base Nacional Comum Curricular (BNCC).

PALAVRAS-CHAVE: Nietzsche; Educação; Crítica; LDB; BNCC.

\section{ON THE RELEVANCE AND RELEVANCE OF NIETZSCHE'S CRITICISMS OF THE EDUCATION OF HIS TIME}

\begin{abstract}
:
This text aims to demonstrate the relevance and relevance of Nietzsche's criticism to the education of his time, especially those made in the text On the future of our educational establishments, in view of the purposes and objectives of Brazilian education, especially of basic education in high school, described in the Law of National Education Guidelines and in The Common National Curricular Base.
\end{abstract}

KEYWORKS: Nietzsche; Education; Criticism; LDB; BNCC.

${ }^{1}$ Doutor(a) em Filosofia pela Pontifícia Universidade Católica do Rio Grande do Sul (PUC/RS), Porto Alegre - RS, Brasil. Professor(a) da Universidade Federal do Piauí (UFPI), Teresina - PI, Brasil.

SOUSA, José Elielton de. Sobre a atualidade e pertinência das críticas de Nietzsche à educação de seu tempo. Griot : Revista de Filosofia, Amargosa - BA, v.21 n.3, p.88-98, outubro, 2021. 


\section{Introdução}

Entre janeiro e março de 1872, o então jovem Friedrich Nietzsche, com apenas 27 anos de idade, proferiu a série de conferências intitulada Sobre o futuro dos nossos estabelecimentos de ensino (2004) a uma plateia de estudantes, intelectuais e personalidades ilustres da Universidade da Basiléia, onde ele ingressara como professor de filologia clássica. $\mathrm{O}$ "professor" Nietzsche sonhava com uma educação (bildung) e uma cultura ligadas à vida e não apenas um ensino profissionalizante que servisse somente a um mesquinho pragmatismo. Sua preocupação é com uma concepção de educação como formadora e difusora cultural, tendo por referência a "cultura clássica" em contraposição ao que denominou de cultura jornalística ou imediata, em processo avançado de consolidação na Alemanha recém unificada após a guerra de 1871 (DIAS, 1993).

Embora seu aristocratismo intelectual não seja condizente com a defesa contemporânea de uma concepção de educação democrática e inclusiva, ao avaliar a educação de sua época e os processos pedagógicos nela utilizados, Nietzsche acaba por estabelecer as bases para uma das críticas mais contundentes à educação moderna, qual seja seu caráter utilitário, técnico e especializado, na medida em que os processos educacionais ali implementados, embora guardem traços bem específicos do contexto alemão, se tornaram referência educacional para os diversos Estados modernos que tomaram para si o papel de condutores da cultura. A instrução em contraposição à formação, a especialização, o tecnicismo e tantos outros indícios dessa "pseudocultura" identificados por Nietzsche se intensificaram no mundo contemporâneo, inclusive no seio da Universidade, a ponto de aceitarmos com muita naturalidade que vivemos numa "cultura da informação", onde o excesso de informações é tudo, menos conhecimento.

As diversas reformas educacionais mundo afora, todas promovidas por agências governamentais nacionais e internacionais ou por grandes corporações mercadológicas, o próprio processo de mercantilização da educação, visam cada vez mais atender às demandas de uma economia globalizada, interessada em mão-de-obra qualificada e na potencialização do consumo. $\mathrm{Na}$ educação básica, especialmente no ensino médio, foco da crítica nietzschiana aos estabelecimentos de ensino de sua época, tanto no Brasil como em outros países periféricos, as reformas promovidas por seus governos e essas agencias vêm aprofundando justamente esse caráter tecnicista e mercadológico da educação, aligeirando seus processos formativos e empobrecendo as capacidades cognitivas, imaginativas e experienciais dos educandos e das educandas.

Nesse sentido, o presente texto visa demonstrar a atualidade e a pertinência da crítica de Nietzsche à educação do seu tempo perante as finalidades e objetivos da educação brasileira, especialmente da educação básica em nível médio, descritos na Lei de Diretrizes e Bases da Educação Nacional (LDB) e na Base Nacional Comum Curricular (BNCC).

\section{Da massificação e da utilidade da educação ontem e hoje}

José Carlos Libâneo nos lembra que a educação é uma atividade humana imprescindível à sua existência e ao funcionamento das sociedades, sendo um fenômeno social e universal. Isso porque cada sociedade precisar cuidar da formação dos indivíduos, auxiliando no desenvolvimento de suas capacidades físicas e espirituais, preparando-os para a participação ativa e transformadora nas várias instâncias da vida social (LIBÂNEO, 1994, p. 15).

Em sentido amplo, a educação corresponde, então, a um processo de formação abrangente, cujas influências e inter-relações convergem para o desenvolvimento de traços de personalidade social e do caráter, implicando concepções de mundo, ideais valorativos, modos de agir, que se

SOUSA, José Elielton de. Sobre a atualidade e pertinência das críticas de Nietzsche à educação de seu tempo. Griot : Revista de Filosofia, Amargosa-BA, v.21 n.3, p.88-98, outubro, 2021. 
traduzem em convicções morais, politicas, princípios de ação frente aos desafios da vida. Em sentido estrito, "a educação ocorre em instituições específicas, escolares ou não, com finalidades explicitas de instrução e ensino mediante uma ação consciente, deliberada e planificada, embora sem separar-se daqueles processos formativos gerais" (LIBÂNEO, 1994, p. 15).

Com a consolidação dos Estados modernos e a necessidade de organização escolar sólida, capaz de oferecer formação para cidadania e qualificação para o trabalho, estes tomam para si tal tarefa de condutor educacional e cultural. Partindo do exemplo "bem-sucedido" do Estado prussiano, várias leis nacionais foram promulgadas mundo afora visando tornar a educação um direito dos cidadãos e um dever do Estado não só garantir esse direito, mas também prover instalações, professores, currículos e sistemas avaliativos. No Brasil, embora o processo de organização sistemática e institucional da educação remete ao período colonial, é somente a partir da década de 1930, no governo de Getúlio Vargas, que o Estado assume tal tarefa de regulação, organização e avaliação do sistema nacional de educação, através da chamada Reforma Francisco Campos (DALLABRIDA, 2009).

Dentre as diversas reformas que ocorrem desde então, é somente com a redemocratização após o final do período ditatorial militar e a promulgação da Constituição de 1988 que esse processo de universalização do acesso à educação pública, fundamentalmente em nível de educação básica, é assumido em sua inteireza pelo Estado brasileiro, expressa de forma enfático através da lei 9.394/1996, Lei de Diretrizes e Bases da Educação Nacional (LDB). Eis o que está escrito no seu Art. $4^{\circ}$ : “O dever do Estado com educação escolar pública será efetivado mediante a garantia de [da] educação básica obrigatória e gratuita dos 4 (quatro) aos 17 (dezessete) anos de idade". Esse compromisso é reafirmado no Plano Nacional de Educação (PNE) publicado em 2014 através da Lei 13.005/2014, onde consta, entre outras metas, "universalizar o ensino fundamental de 9 (nove) anos para toda a população de 6 (seis) a 14 (quatorze) anos, bem como "universalizar [...] o atendimento escolar para toda a população de 15 (quinze) a 17 (dezessete) anos e elevar, até o final do período de vigência deste PNE, a taxa líquida de matrículas no ensino médio para $85 \%$ (oitenta e cinco por cento)".

Além disso, outra inovação trazida pela LDB é a ideia de currículo comum para os sistemas de ensino. $\mathrm{O}$ Art. $26^{\circ}$ prevê que os currículos da educação básica "devem ter uma base nacional comum, a ser complementada, em cada sistema de ensino e em cada estabelecimento escolar, por uma parte diversificada, exigida pelas características regionais e locais da sociedade, da cultura, da economia e dos educandos", sendo competência do Conselho Nacional de Educação (CNE) aprovar a inclusão ou exclusão de novos componentes curriculares obrigatórios. Essa previsão se efetivou por meio da publicação, em 2017, da Base Nacional Comum Curricular, documento de caráter normativo que define o conjunto orgânico e progressivo de aprendizagens essenciais que todos os alunos devem desenvolver ao longo das etapas e modalidades da Educação Básica (BRASIL, 2017b, p. 7).

Ora, era justamente esse caráter compulsório e massivo da educação de seu tempo uma das tendências nefastas identificadas por Nietzsche. Segundo ele, duas correntes aparentemente opostas, mas complementares, ambas nefastas nos seus efeitos, dominam os estabelecimentos de ensino moderno: "por um lado, a tendência de estender tanto quanto possível a cultura, por outro lado, a tendência de reduzi-la e enfraquecê-la" (NIETZSCHE, 2004, p. 44). Contra a primeira tendência de levar a cultura a círculos cada vez mais amplos, ocasionando a criação de "homens comuns", voltados para a busca da felicidade identificada com a utilidade e o dinheiro, o filósofo propõe seu estreitamento e sua concentração; contra a segunda tendência de reduzir a cultura a um mero instrumento útil e funcional, que abandone sua soberania e se submeta à crescente especialização, ele propõe seu fortalecimento e sua soberania (NIETZSCHE, 2004, p. 44-45).

SOUSA, José Elielton de. Sobre a atualidade e pertinência das críticas de Nietzsche à educação de seu tempo. Griot : Revista de Filosofia, Amargosa - BA, v.21 n.3, p.88-98, outubro, 2021. 
Chamar atenção para esses aspectos de nosso sistema educacional não significa questionar ou ignorar a importância fundamental da educação para as pessoas e da democratização de seu acesso, especialmente num país periférico e profundamente desigual como o nosso, mas atentar para outras questões de ordem não-educacionais presentes nesse processo de condução da política educacional por parte do Estado. Através da análise das duas tendências acima mencionadas da educação de sua época, pautada pela emergência das massas urbanas e a "questão social", junto com a intervenção do Estado na educação, Nietzsche percebe, por exemplo, que "a cultura mais universal [da modernidade] é exatamente a barbárie" (NIETZSCHE, 2004, p. 62). Essa "barbárie cultivada", que reduz tudo à utilidade e à especialidade, na qual inclusive um erudito passara a uma condição análoga a do operário de fábrica, distante e alienada da cultura autêntica, produz uma "pseudocultura" que, por sua vez, concorre para o advento da barbárie.

Como resultado da confluência dessas tendências, o jornalista assume o papel de sábio: “é no jornal que culmina o desígnio particular que nossa época tem sobre cultura: o jornalista, o senhor do momento, tomou o lugar do grande gênio, do guia estabelecido para sempre, daquele que livra do momento atual (NIETZSCHE, 2004, p. 65). Frente a essa "fidelidade nas pequenas coisas", o professor perde o seu trabalho pedagógico por causa do jornal, do romance folhetim e do livro do especialista, "cujo estilo já traz consigo os brasões repugnantes da barbárie cultivada que está em curso hoje em dia" (NIETZSCHE, 2004, p. 65). Guardadas as devidas proporções, tal diagnóstico não difere muito da condição atual, onde os professores e as professoras têm seu trabalho pedagógico reduzido a "fórmulas prontas" ditadas pelas "técnicas de formação" implementadas pela gestão escolar especializada, os aparelhos tecnológicos e os aplicativos ditam o ritmo e os recursos a serem utilizados em sala e os youtubers são as novas "referências".

Para Nietzsche, o ginásio (equivalente ao nosso ensino médio) é o centro motor dos estabelecimentos de ensino, inclusive da universidade: "todas as outras instituições devem medirse pelo objetivo cultural que é visado pelo ginásio, pois elas sofrem com os desvios de sua tendência, e assim serão também purificadas e renovadas com sua purificação e renovação" (NIETZSCHE, 2004, p. 68). No entanto, os ginásios de sua época não apresentavam as condições necessárias para desempenhar tal função de formação de uma cultura superior. A língua materna, por exemplo, núcleo de toda autêntica cultura, era aí ensinado de maneira grosseira, superficial e jornalística. Ao que parece, a expansão da rede de ensino não foi acompanhada pela expansão da qualidade da mesma, um desafio que outros lugares também enfrentaram e enfrentam nesse processo de massificação da educação básica (Cf. RODRIGO, 2009).

Além disso, Nietzsche censura inclusive os métodos didático-pedagógicos dos ginásios de sua época por focarem na liberdade, na autonomia e na expressão livre da personalidade dos adolescentes numa idade em que eles ainda não estavam preparados para tanto. No ginásio, os jovens são considerados, sem muito rigor, como capazes de fazer literatura, com o direito de ter opiniões pessoais, “embora uma educação correta devesse justamente aspirar, com todos os seus esforços, reprimir as ridículas pretensões de autonomia de julgamento e apenas habituar o jovem a uma estrita obediência sob a autoridade do gênio" (NIETZSCHE, 2004, p. 73). Em suma, os ginásios da época, não passavam de instituições transmissoras de uma educação uniforme e medíocre, utilitária e integradora, baseada no princípio da "livre personalidade", cujo efeito era conservar os jovens na imaturidade, na ignorância e na indiferença (SOBRINHO, 2004, p. 12).

Além disso, a atuação do Estado como mentor e guia da educação e da cultura, um fenômeno moderno exemplificado no Estado prussiano, a qual impõe como necessidade absoluta, como lei fundamental das coisas, aquilo que é fundamental para os próprios fins do estado, é uma grave ameaça à verdadeira cultura. Para o filósofo, a única coisa que o Estado pode fazer em prol de um excesso de estabelecimentos de ensino é "estabelecer uma relação necessária entre ginásio

SOUSA, José Elielton de. Sobre a atualidade e pertinência das críticas de Nietzsche à educação de seu tempo. Griot : Revista de Filosofia, Amargosa - BA, v.21 n.3, p.88-98, outubro, 2021. 
e os postos mais elevados da classe de funcionários, e também com uma grande parte dos cargos menos elevados, com o acesso à Universidade, e mesmo com os privilégios militares de maior amplitude" (NIETZSCHE, 2004, p. 97-98). Foi exatamente dessa forma que agiu o Estado prussiano, empregando o mais poderoso de seus recursos, a atribuição de certos privilégios que se referem ao serviço militar, criando uma imperiosa e contínua necessidade de instauração de novas escolas diante da saturação das existentes.

Essa associação entre um "Estado cultural" e a "mentalidade jornalística" leva Nietzsche a desconfiar seriamente das intenções culturais do Estado militarista prussiano, admirado por outros Estados e em todo lugar imitado. O Estado, ao se apresentar como objetivo supremo de todos os esforços culturais, destrói os verdadeiros impulsos para a cultura, reduz a finalidade da educação a mera questão de sobrevivência, seja como funcionário público ou militar, e corrompe as "naturezas dotadas" ao distribuir pequenos privilégios com o objetivo de atraí-las para seus desígnios. O Estado torna-se, portanto, "mistagogo da cultura" e, ao tempo em que persegue seus próprios fins, obriga a todos seus servidores a reconhecerem nele aquele que recompensa todos os seus esforços na direção da cultura.

É importante observar que Nietzsche não é contra o ginásio e muito menos ainda contra as escolas técnicas e primárias: "eu honro os lugares onde se aprende a calcular adequadamente, onde se domina a língua, onde se leva a sério a geografia, onde se é instruído pelos conhecimentos admiráveis que nos dão as ciências naturais" (NIETZSCHE, 2004, p. 106). O filósofo reconhece inclusive que os estudantes das escolas técnicas devem ter os mesmos direitos que se tem o costume de atribuir aos estudantes do ginásio no final dos estudos, inclusive o acesso à Universidade e à administração pública.

Seu combate é contra a confusão moderna entre formação para a cultura e instrução para as necessidades da vida. Nietzsche observa que o Estado, infelizmente, ao se atribuir a função de estrela-guia da cultura, impôs às escolas técnicas e ao ginásio da época certas semelhanças que o tornam praticamente iguais, não havendo, portanto, uma instituição de ensino responsável pela cultura. Ao contrário das escolas técnicas, o ginásio não dispunha de honestidade na perseguição de seus objetivos e seus professores dissimulam seu desespero e seu descontentamento com tal estabelecimento de ensino criticando o realismo que inspirava as escolas técnicas (NIETZSCHE, 2004, p. 106). A contradição essencial está, portanto, no ginásio, centro motor de toda verdadeira cultura: "só conheço uma única verdadeira oposição, aquela que existe entre os estabelecimentos para a cultura e os estabelecimentos para as necessidades da vida; à segunda categoria pertencem todos os estabelecimentos de ensino que existem, mas, ao contrário, é da primeira que falo" (NIETZSCHE, 2004, p. 107).

Aliás, essa contradição pode ser encontrada inclusive na nossa própria LDB quando afirma em seu Art. $2^{\circ}$ que "a educação [...] tem por finalidade o pleno desenvolvimento do educando, seu preparo para o exercício da cidadania e sua qualificação para o trabalho", numa tentativa de conciliar "formação integral" com "preparação básica para o trabalho e a cidadania". Ora, embora evidencie um entendimento mais amplo da função social da educação, essa relação entre a educação e o mundo do trabalho se manterá fortemente presente nos documentos oficiais complementares à LDB que tratam de currículos, conteúdos, metodologias e formas de avaliação processual e formativa da educação básica e acaba por se sobressair sobre os aspectos da formação em geral.

É o que deixa transparecer, por exemplo, a Lei 13.415/2017, que altera consideravelmente as diretrizes e bases da educação nacional proposto na lei 9.394/1996 e propõe um "novo" ensino médio, na medida em que os conteúdos, as metodologias e as formas de avalição processual e formativa visam demonstrar que ao final do ensino médio os educandos e as educandas tenham

SOUSA, José Elielton de. Sobre a atualidade e pertinência das críticas de Nietzsche à educação de seu tempo. Griot : Revista de Filosofia, Amargosa - BA, v.21 n.3, p.88-98, outubro, 2021. 
“domínio dos princípios científicos e tecnológicos que presidem a produção moderna" (BRASIL, 2017a, p. 26). A própria compreensão da ideia de "itinerários formativos" que essa nova lei traz evidencia isso, pois seu Art. $3^{\circ}$, que altera o Art. $36^{\circ}$ da Lei 9.394/1996, em seu $\S^{\circ}$ está descrito quais as expectativas que devem serem cumpridas pelos educandos e pelas educandas para sejam considerados "integralmente formados", qual seja, demonstrar: "I - Domínio dos princípios científicos e tecnológicos que presidem a produção moderna; II - Conhecimento das formas contemporâneas de linguagem" (BRASIL, 2017a).

Além disso, essa nova lei, em seu Art. $36, \S 6^{\circ}$, flexibiliza o processo de certificação intermediaria para aqueles que optarem pelo itinerário voltado para educação profissional, aligeirando e precarizando a formação profissional, passando a considerar:

I - A inclusão de vivências práticas de trabalho no setor produtivo ou em ambientes de simulação, estabelecendo parcerias e fazendo uso, quando aplicável, de instrumentos estabelecidos pela legislação sobre aprendizagem profissional;

II - A possibilidade de concessão de certificados intermediários de qualificação para o trabalho, quando a formação for estruturada e organizada em etapas com terminalidade. (BRASIL, 2017a)

Os reflexos dessas alterações, no sentido de aprofundamento do caráter utilitário e tecnicista da educação básica brasileira, estão expressos de forma mais clara na Base Nacional Comum Curricular (BNCC). Nesse documento, a aprendizagem é compreendida fundamentalmente como um processo que visa assegurar aos educandos e às educandas o desenvolvimento de competências definida como "a mobilização de conhecimentos (conceitos e procedimentos), habilidades (práticas, cognitivas e socioemocionais), atitudes e valores para resolver demandas complexas da vida cotidiana, do pleno exercício da cidadania e do mundo do trabalho" (BRASIL, 2017b, p. 8). Na contramão da crítica nietzschiana, ao enfatizar o "saber fazer", a aplicabilidade prática, focada nas "habilidades", nas "competências", nos "procedimentos" e na "formação de atitudes", e não destacar os conteúdos escolares, o trabalho educativo e o ensinar, "o documento traz uma perspectiva que visa adaptar os alunos ao mercado de trabalho ou, mais propriamente, ao "empreendedorismo" (MARSIGLIA, PINA, MACHADO \& LIMA, 2017, p. 119).

Além disso, embora preconize uma "formação integral", a BNCC aprofunda o caráter fragmentário e especializado do conhecimento ao propor os “itinerários formativos", reduzir parte das disciplinas de Humanidades a meros "estudos e práticas" e "privilegiar" o itinerário profissionalizante, "facilitando" o processo de certificação e mantendo como obrigatório apenas disciplinas ligadas à este itinerário em todo o ensino médio, como língua portuguesa e matemática. Em relação aos itinerários formativos, o próprio texto da BNCC confirma esse caráter fragmentário e especializado acima apontado ao dizer que "essa nova estrutura valoriza o protagonismo juvenil, uma vez que prevê a oferta de variados itinerários formativos para atender à multiplicidade de interesses dos estudantes: o aprofundamento acadêmico e a formação técnica profissional" (BRASIL, 2017b, p. 467). Como podemos falar em “educação integral" se, em função das determinações da Lei 13.415/2017, apenas as disciplinas de língua portuguesa e matemática são consideradas componentes curriculares obrigatórios nos três anos do ensino médio, sendo os demais componentes condicionados à relevância para o contexto local e às possibilidades dos sistemas de ensino em ofertá-los?

Com isso, a ideia inicial de uma formação básica integral, através de objetivos mais abrangentes para o ensino médio que perpassam pelo prosseguimento dos estudos e o aprimoramento como pessoa humana, preconizada pela versão da LDB proposta pela Lei 
9.393/1996, tentando assim superar o contraste em entre o caráter profissionalizante e o caráter propedêutico do ensino médio, vai se perdendo. Com a Lei 13.415/2017 e sua efetivação através da BNCC, o "novo" ensino médio proposto intensifica o caráter utilitarista, fragmentado e profissionalizante do conhecimento, aprofundando ainda mais o abismo existente entre ensino propedêutico/profissionalizante e a formação humana integral. Com isso, a crítica nietzschiana à educação de seu tempo e sua defesa de estabelecimentos de ensino para formação cultural, e não apenas para as necessidades da vida, se mostra não só atual, mas extremamente relevante para esse contexto contemporâneo de proliferação de "modelos" educacionais seriais, massificados, homogeneizados e economicamente demandados.

\section{Formação para a cultura versus instrução para as necessidades da vida}

Se Nietzsche tinha razão acerca das críticas à educação do seu tempo, o que ele propõe então como alternativa? Dito de outra forma, em que consistiria, então, um estabelecimento de ensino para a cultura nos termos em que Nietzsche está pensando? Não é necessário ressaltar que se trata de um grupo com pouco número de indivíduos, com sólida organização e com um sentido muito claro e determinado de sua missão, qual seja, "preparar o nascimento do gênio e a criação de sua obra" (NIETZSCHE, 2004, p. 117). Todos aqueles que participam deste tipo de estabelecimento de ensino, ainda que seus dons sejam de segunda ou terceira ordem, estão destinados à tal colaboração e só chegam ao sentimento de viver para seu dever servindo a estas autênticas instituições de cultura. Nesse sentido, o filósofo propõe, então, uma nova concepção de cultura, cuja característica principal é, "antes de mais nada, [...] uma obediência e uma habituação à disciplina que caracteriza o gênio" (NIETZSCHE, 2004, p. 118). Ao contrário da pseudocultura moderna, toda cultura autêntica começa, nos termos nietzschianos, "com a obediência, com a disciplina, com a instrução, com o sentido do dever" (NIETZSCHE, 2004, p. $135)$.

Assim, em tal cultura elevada, marcada pela figura do gênio, a educação deve consistir justamente num processo que possibilite o cultivo destes tipos superiores, pois "assim como os grandes guias têm necessidade de homens para conduzir, também aqueles que devem ser conduzidos têm necessidade de guias: a proposito disso, na ordem do espírito, reina uma predisposição mútua (NIETZSCHE, 2004, p. 135-136).

Nietzsche parte do princípio segundo o qual "todo homem é um milagre irrepetível”, para contrapor essa singularidade que é o gênio ao animal de rebanhos moderno, preguiçoso e indulgente (NIETZSCHE, 2004, p. 138). O homem moderno, talvez por pudor, indolência, comodismo ou mesmo preguiça, não se vê como singular e múltiplo, escondendo-se atrás de costumes e opiniões, pensando e agindo como animal de rebanhos. E para o filósofo, "não existe na natureza criatura mais sinistra e mais repugnante do que o homem que foi despojado do seu próprio gênio e que se extravia agora a torto e a direito, em todas as direções" (NIETZSCHE, 2004, p. 139).

Como seria possível, então, se libertar de tal cultura de rebanhos, desse "comportamento indiferente das mercadorias fabricadas em série", e conhecer-se a si mesmo, como nos encontrar a nós mesmos? Nietzsche ressalta que se trata de algo obscuro e velado, de uma empreitada penosa e perigosa, pois implica cavar em si mesmo e descer à força, pelo caminho mais curto, aos poços do próprio ser - e com que facilidade, então, ele se arrisca a se ferir, tão gravemente que nenhum médico poderia curá-lo (NIETZSCHE, 2004, p. 141). Isso porque aquilo que chamamos de eu não é apenas a nossa interioridade, mas também o que está acima de nós e que nos faz ser o que somos - os objetos que veneramos, as nossas amizades e os nossos ódios, o nosso olhar e o estreitar da

SOUSA, José Elielton de. Sobre a atualidade e pertinência das críticas de Nietzsche à educação de seu tempo. Griot : Revista de Filosofia, Amargosa - BA, v.21 n.3, p.88-98, outubro, 2021. 
nossa mão, a nossa memória e o nosso esquecimento, os nossos livros e os traços da nossa escrita, em suma, a própria vida.

Nietzsche reconhece que existem outros meios de encontrar a si mesmo, mas certamente o melhor caminho é aquele indicado pelos verdadeiros mestres e educadores, cuja figura exemplar é Schopenhauer. É que o filósofo procura um tipo que possa servir de exemplo, não apenas pelos livros ou pelos discursos, mas fundamentalmente pela vida: um exemplo que "deve portanto ser dado, como ensinavam os filósofos da Grécia, pela expressão do rosto, pela vestimenta, pelo regime alimentar, pelos costumes, mais ainda do que pelas palavras e sobretudo mais do que pela escrita" (NIETZSCHE, 2004, p. 150).

No entanto, engendrar um gênio numa época tão bárbara e apequenada como a época moderna não é uma tarefa fácil, mas algo milagroso e de grande significado, na medida em que monstruosos perigos cercam quem tenta elevar-se até chegar a ser este modelo humano. E o Schopenhauer educador de Nietzsche teve que enfrentar três grandes perigos que são inerentes a esse processo de diferenciação do rebanho: (1)o isolamento ou o asilo onde nenhum tirano pode penetrar; (2) o desespero da verdade que não se reduz à busca da coisa-em-si; (3) a nostalgia e a melancolia causadas pelos limites de nossos dons que podem romper com o liame que separa o ser humano do ideal que ele aspira (Cf. NIETZSCHE, 2004, p. 151-159).

Estes três perigos constitutivos que ameaçam Schopenhauer também nos ameaçam a todos, pois cada um deles carrega consigo uma unicidade produtiva que a maioria das pessoas consideram insuportável por se ligar a toda uma cadeia de fardos e tormentos. É por ter atravessado todos estes perigos, ainda que com muitas cicatrizes e feridas abertas ou mesmo num estado de espírito que parece grave ao extremo e às vezes também muito belicoso, que Schopenhauer é um filósofo que educa: o que havia de mais imperfeito e de demasiado humano no ser de Schopenhauer "é precisamente o que mais nos aproxima dele, no sentido mais humano da palavra, pois o vemos então como um ser sofredor e como um companheiro de sofrimento, e não mais somente imerso na elevação desdenhosa do gênio" (NIETZSCHE, 2004, p. 159).

É preciso perguntar, então, como é possível nos aproximar desta condição elevada, de maneira que ela nos eduque, elevando tudo em nós? Para o filósofo, "este é o pensamento fundamental da cultura, na medida em que esta só pode atribuir um única tarefa a cada um de nós: incentivar o nascimento do filósofo, do artista e do santo em nós e fora de nós, e trabalhar assim para a realização [Vollendung] da natureza" (NIETZSCHE, 2004, p. 180). Através destes "homens verdadeiros", a natureza, que jamais dá saltos, dá seu único salto rumo à sua finalidade, alcançando sua realização e culminância. Nesse sentido, “o papel da educação é então libertar estas forças interiores que a natureza colocou nos homens para a sua elevação e realização: as forças instintivas e plásticas que permitem a eles realizar suas obras, sobretudo as obras mais elevadas" (SOBRINHO, 2004, p. 34).

Nietzsche reconhece que é difícil levar alguém a atingir este estado de conhecimento impávido de si, porque é impossível ensinar o amor - "pois é no amor que a alma adquire, não somente uma visão clara, analítica e desdenhosa de si, mas também este desejo de olhar acima de si e buscar com todas as suas forças um eu superior, ainda oculto não sei onde" (NIETZSCHE, 2004, p. 183). A soma de estados interiores, essa mistura de conhecimento impávido de si e de vergonha de si por ter deixado o gênio sem tréguas arrastar-se a este torpor, é a primeira consagração da cultura. Além destes perigos de toda constituição interna, aos quais Schopenhauer esteve exposto, há também os perigos da época que impedem o engendramento do gênio, os quais são essenciais para compreender ainda mais claramente o que há de exemplar e educador na natureza de Schopenhauer. 
O egoísmo dos negociantes que tem necessidade do auxílio da cultura é o primeiro destes perigos, pois relacionam conhecimento e cultura à produção de mais lucro. Seu princípio e raciocínio é o seguinte: "quanto mais houver conhecimento e cultura, mas haverá necessidades, portanto, também mais produção, lucro e felicidade - eis aí a falaciosa fórmula" (NIETZSCHE, 2004, p. 185). A finalidade da educação para os partidários desta perspectiva é formar o maior número possível de "homens correntes", no sentido de "moeda corrente", levando cada um a reproduzir o modelo "corrente" e a educar de tal maneira que se extraia do seu próprio conhecimento e saber a maior quantidade possível de felicidade e lucro.

O segundo perigo é o egoísmo do Estado que deseja também a extensão e a generalização maior da cultura e que tem nas mãos os instrumentos mais eficazes para satisfazer os seus desejos. Assim, se o Estado sabe de sua força para, não apenas desentravar, mas impor seu jugo em tempo útil, a difusão da cultura entre seus cidadãos somente aproveitará a ele mesmo, na sua rivalidade com os outros Estados.

O terceiro perigo é o egoísmo dos artistas e que se resume na "bela forma" como refinamento da arte. Consciente de possuírem um conteúdo de fealdade e de tédio em relação à vida, eles fazem o avesso do seu instinto, isto é, tentam preenchê-la com formas abstratas e vazias em um ideal de perfeição que está longe do devir da cultura ligada à vida: “com os detalhes exteriores, a palavra, o gesto, com a decoração, o fausto e as boas maneiras, trata-se de obrigar o espectador a uma falsa conclusão quanto ao conteúdo: admitido que se julga habitualmente o interior segundo o exterior" (NIETZSCHE, 2004, p. 187).

O último perigo elencado por Nietzsche é o egoísmo da ciência dos eruditos que despreza o sofrimento e preocupa-se apenas com uma questão de lógica. A ciência é fria e árida, ela não tem amor e ignora tudo com um profundo sentimento de insatisfação e nostalgia: "ela é útil apenas a si mesma, tanto quanto é nociva a seus servidores, na medida em que transpõe neles seu caráter próprio e assim ossifica de alguma maneira sua humanidade" (NIETZSCHE, 2004, p. 191). O erudito da ciência, este "servidor da verdade", é uma espécie de síntese exemplar da cultura utilitária moderna, onde a luta pela verdade seria apenas um pretexto para suas vitorias e prazeres pessoais, pois "por servilismo para com certas pessoas, para com as castas, para com as opiniões, as igrejas e os governos estabelecidos, porque ele percebe que presta um serviço a si mesmo colocando a "verdade' do lado destes" (NIETZSCHE, 2004, p. 192).

Para o filósofo, a junção de todos estes elementos, de um grande número deles, ou somente de alguns, traz à tona um fenômeno surpreendente: "assiste-se então o nascimento do servidor da verdade" (NIETZSCHE, 2004, p. 196). O erudito, tal como descrito, é culturalmente infecundo e experimenta um certo ódio natural contra o "homem fecundo", o gênio. Os eruditos querem matar, dissecar, compreender a natureza; [os gênios] querem acrescentar à natureza uma nova natureza viva; além disso, há um conflito de opiniões e de atividades [entre o gênio e o erudito]" (NIETZSCHE, 2004, p. 196).

À guisa de considerações finais, poderíamos nos perguntar, então, quais seriam as condições que proporcionariam o nascimento do gênio? Para Nietzsche, a época moderna não possui uma solidez assentada e durável no que diz respeito à crença numa significação metafisica da cultura, o que exigiria uma reflexão completamente incomum a partir e para além das instituições pedagógicas de seu tempo. $O$ indivíduo que compreendeu este novo pensamento fundamental da cultura se encontra numa encruzilhada entre dois caminhos: o primeiro tem como objetivo a manutenção da instituição da cultura e a eliminação dos rebeldes e dos solitários e de todos os que visam a objetivos mais elevados; o segundo é mais difícil, mais tortuoso, mais escarpado, e visa a criação de uma instituição da cultura que não seja arrastada pela torrente do

SOUSA, José Elielton de. Sobre a atualidade e pertinência das críticas de Nietzsche à educação de seu tempo. Griot : Revista de Filosofia, Amargosa - BA, v.21 n.3, p.88-98, outubro, 2021. 
rebanho e que os indivíduos que a compõem não sucumbam a um esgotamento prematuro, ou seja, fiquem desencantados com a sua grande tarefa (NIETZSCHE, 2004, p. 198).

As condições de possibilidade de nascimento do gênio filosófico na época moderna, apesar das nefastas influências contrárias, estão relacionadas ao estudos e ao exercício da reflexão filosófica, não certamente a filosofia que é destilada nas universidades e nos estabelecimentos de ensino em geral, esta filosofia que "não comove ninguém", mas uma filosofia que seja a manifestação direta da natureza que quer tornar sua existência inteligível através dos "homens extraordinários", dos quais Schopenhauer é um exemplar. Resta saber se tal projeto ainda é possível no contexto contemporâneo, se dispomos de condições materiais e disposições espirituais para engendrar excepcionalidades extraordinárias, capazes de nos redimir da barbárie em que estamos mergulhados.

Não é sem razão que Karl Löwith afirma que a crítica de Nietzsche à educação de sua época é antes de tudo, e no final das contas, uma crítica ao mundo contemporâneo (LÖWITH, 2014). E não deixa de ser irônico o fato de que, embora Nietzsche considerasse em Sobre o futuro dos nossos estabelecimentos de ensino a maior das presunções alguém querer ser profeta, ele acabara por se tornar, em grande medida, um profeta do mundo contemporâneo.

SOUSA, José Elielton de. Sobre a atualidade e pertinência das críticas de Nietzsche à educação de seu tempo. Griot : Revista de Filosofia, Amargosa - BA, v.21 n.3, p.88-98, outubro, 2021. 


\section{Referências}

BRASIL. Base Nacional Comum Curricular. Brasília, Ministério da Educação. 2017b.

BRASIL. Lei de Diretrizes e Bases Da Educação Nacional. Lei n ${ }^{\circ}$ 9.394, de 20 de dezembro de 1996. Brasília, DF: Senado Federal, 1996.

BRASIL. Lei $n^{\circ} 13.415$, de 16 de fevereiro de 2017. Altera as Leis $\mathbf{n}^{\circ}$ s 9.394, de 20 de dezembro de 1996, que estabelece as diretrizes e bases da educação nacional, e 11.494, de 20 de junho 2007, que regulamenta o Fundo de Manutenção e Desenvolvimento da Educação Básica e de Valorização dos Profissionais da Educação, a Consolidação das Leis do Trabalho - CLT; revoga a Lei N $^{o}$ 11.161, de 5 de agosto de 2005; e institui a Política de Fomento à Implementação de Escolas de Ensino Médio em Tempo Integral. Brasília, DF: Senado Federal, 2017a.

DALLABRIDA, Norberto. A reforma Francisco Campos e a modernização nacional do ensino secundário. Educação, v. 32, nº 2, p. 185-191, 2009.

DIAS, Rosa Maria. Nietzsche educador. São Paulo: Scipione, 1993.

FRAGOSO, Myrian Xavier. Nietzsche e a educação. Trans/Form/Ação, vol.1, p. 277-293, 1974.

LIBÂNEO, José Carlos. Didática. São Paulo: Cortez, 1994.

LÖWITH, K. De Hegel à Nietzsche: a ruptura revolucionária no pensamento do século XIX - Marx e Kierkegaard. Tradução de Luiz Fernando Barrére Martin e Flamarion Caldeira Ramos. São Paulo: Editora UNESP, 2014.

MARSIGLIA, Ana Carolina Galvão; PINA, Leonardo Docena; MACHADO, Vinícius de Oliveira; LIMA, Marcelo. A Base Nacional Comum Curricular: um novo episódio de esvaziamento da escola no Brasil. Germinal: Marxismo e Educação em Debate, v. 9, nº 1, p. 107-121, 2017.

MARTON, Scarlett. Nietzsche: das forças cósmicas aos valores humanos. $2^{\mathrm{a}}$ ed. Belo Horizonte: Ed. UFMG, 2000.

NIETZSCHE, F. III Consideração intempestiva: Schopenhauer educador. IN: Escritos sobre Educação. Tradução, apresentação e notas de Noéli Correia de Melo Sobrinho. $2^{\text {a }}$ ed. Rio de Janeiro: Editora PUC-Rio; São Paulo: Loyola, 2004.

NIETZSCHE, F. Sobre o futuro dos nossos estabelecimentos de ensino. IN: Escritos sobre Educação. Tradução, apresentação e notas de Noéli Correia de Melo Sobrinho. $2^{\text {a }}$ ed. Rio de Janeiro: Editora PUC-Rio; São Paulo: Loyola, 2004.

RODRIGO, L. M. Filosofia em sala de aula: teoria e prática para o ensino médio. Campinas, SP: Autores Associados, 2009.

SOBRINHO, Noéli Correia de Melo. A pedagogia de Nietzsche. IN: NIETZSCHE, F. Escritos sobre Educação. Tradução, apresentação e notas de Noéli Correia de Melo Sobrinho. $2^{\text {a }}$ ed. Rio de Janeiro: Editora PUC-Rio; São Paulo: Loyola, 2004.

Autor(a) para correspondência / Corresponding author: José Elielton de Sousa.jose_elielton@yahoo.com.br

SOUSA, José Elielton de. Sobre a atualidade e pertinência das críticas de Nietzsche à educação de seu tempo. Griot : Revista de Filosofia, Amargosa - BA, v.21 n.3, p.88-98, outubro, 2021. 